\title{
A Neurovascular Blood-Flow Modulation Model via Acupuncture Induced Nitric Oxide
}

\author{
Sheng-Hsiung Hsiao \\ Division of Informatics, National Research Institute of Chinese Medicine, Taipei,
}

Taiwan

\section{Introduction}

Acupuncture is a practice of inserting needles into the body to reduce pain or induce anesthesia. More broadly, acupuncture is a family of procedures involving the stimulation of anatomical locations on or beneath the skin by a variety of techniques. Employing acupuncture to treat human illness or to maintain body health has been practiced for thousands of years. Recently, models able to describe the mode of action of acupuncture have aroused scientists' curiosity. Scientific interest in acupuncture has led numerous investigators to conduct clinical trials that have tested the efficacy of acupuncture at various acupuncture points. However, the mechanism(s) of action of acupuncture at the various meridians are still poorly understood.

The traditional Chinese medical theory says: 'Qi acts as the commander of blood and blood acts as the mother of Qi'. This is a general description of the effects of Qi on blood and this theory can be extended to include the ideas that Qi promotes blood circulation and controls the blood functioning. Furthermore blood conveying Qi and blood nourishing Qi.

Previous studies have provided a variety of information regarding the physiological effects of acupuncture on animal and human bodies. Most of them have indicated that acupuncture is able to increase blood flow [1], and at the acupuncture points and meridians have a high electrical conductance [2,3]. A relationship has also been suggested that among those acupuncture points and meridians with connective tissue planes [4] and the perivascular space [5]. A number of possible mechanisms by which acupuncture acts have been reviewed [6].

The results obtained from human and animal studies have shown that acupuncture enhances the generation of nitric oxide (NO) and increases local circulation [7]. Kim, et al. (2006) pointed out that employing acupuncture on stomach 36 point (ST-36) is able to reduce blood pressure by activating NO signaling mechanisms [8]. Ma (2003) showed that NO content and Nitric Oxide Synthase (NOS) expression were consistently higher at skin acupuncture points/meridians [9]. Chen et al. (2005) showed that L-arginine-derived NO synthesis appears to mediate the noradrenergic function of skin sympathetic nerve activation and that this contributes to skin electrical resistance of the acupuncture points and meridians [10].

$\mathrm{NO}$ is known to exert an effect on a number of functions including the regulation of blood pressure, contributing to the immune response, the control of neurotransmission and participation in cell differentiation and other physiological functions [11]. NO, a diffusible 
signaling gas is synthesized by three NOS isoforms, namely neuronal NOS (nNOS), inducible NOS (iNOS) [12] and endothelial NOS (eNOS) [13, 14]. In the cardiovascular system, NO is tonically released by the endothelial cells in response to shear stress to maintain vascular tone [15]. This effect is due to the relaxation of the vascular smooth muscle cells in the medium layer (tunica media) of the arterial wall. However, NO is also involved in the regulation of synaptic neurotransmission, platelet aggregation, inflammation, appetite, peristalsis, renal metabolism, respiratory function, lipid metabolism and glucose metabolism.

It is supposed that the gas (NO) is part of Qi, then the proposed model can be annotated as this part of Traditional Chinese Medical theory. This hypothesis involves a blood-flow modulate model. Briefly, the acupuncture stimulus is able to induce a burst of NO production through mechanotransduction at the local acupuncture point and this NO diffuses and changes the blood flow either at the local and/or organ microcirculation level. Erythrocytes in blood vessel detect the oxygen and modulate vascular tone via controlled NO processing, and this is able to change the frequency of resonance and modulate the vascular tone.

Chinese acupuncture theory has long been recognized that there are twelve main meridians or energy channels that relate to the internal organs. These include the lungs, large intestine, stomach, spleen, heart, the pericardium (the sac around the heart), etc.

Acupuncture induced differential production of $\mathrm{NO}$ in various meridian organs, which are connected via tissue/cells coupled to the cyclically strained blood vessel; vascular blood flow and its distribution among different vascular beds, are regulated by the changes in micro vascular tone.

\section{A neurovascular blood-flow modulation model of acupuncture}

In vascular wall, most of the bioavailable NO is believed to be derived from eNOS and diffuses into vascular smooth muscle and the blood stream, where it rapidly reacts with the hemoglobin $(\mathrm{Hb})$ of the red blood cells. Of course, it is also able to transport oxygen and carbon dioxide. The blood carries the oxygen complex with $\mathrm{Hb}$ to all parts of human body where it is required for metabolism and also returns with carrying carbon dioxide back to the lungs, where gaseous exchange with the atmosphere. The peripheral chemoreceptors located in the carotid bodies respond primarily to hypoxaemia. Central chemoreceptors located in the region of the brainstem respond to hypercapnia. Activation of either the hypoxic or hypercapnic chemoreflex elicits both hyperventilation and sympathetic activation [16]. Evidences from animal and human studies have revealed that NO may play a role in hypercapnia induced vasodilatation $[17,18]$.

Recently, nNOS has been identified as a source of NO in the vicinity of microvessels and has been shown to participate in vascular function. Thus, NO can be produced and transported to the vascular smooth muscle cells from endothelial cells and perivascular nerve fibers, mast cells and other NOS-containing sources [19].

In Chinese terms, "acupuncture is a healing art of inserting a needle into an acupuncture point in the meridian to regulate an imbalance of Qi. The aim of acupuncture is to stimulate the flow of Qi through that meridian."

To explain the Qi phenomenon, we proposed a neurovascular blood-flow modulation model via acupuncture induced NO. 


\subsection{Acupuncture induces mechanotransduction in connective tissue}

Immediately after a needle is inserted into connective tissue, the mechanical force is transferred to the extra cellular matrix (ECM). The ECM is a multi-component tissue that is able to transduce the internal and external mechanical signals into changes in the tissue structure and function through a process termed mechanochemical transduction $[20,21]$.

\subsection{Mechanical force modulates NO production, and mediates the local vascular circulation}

The availability of NO in arteriolar endothelium and mast cells appeared to be maintained mainly by nNOS, whereas that in venular endothelium greatly depends on eNOS. Through the ECM, the mechanical force stimulus can travel across the acupoint into the local tissue cells including arterioles, nerve terminals and mast cells, and this will trigger nNOS induced NO production [9] which diffuses into the vascular smooth muscle and change blood flow and local circulation.

\subsection{NO regulates central nervous system and cardiovascular activities}

Sympathetic cardiovascular rostral ventrolateral medulla (rVLM) neurons that respond to both visceral (reflex) and somatic (acupuncture) nerve stimulation during stimulation of specific acupoints [22]. Nitric oxide (NO) syntheses (NOS)-containing neurons in the rVLM are activated during cardiac sympathoexcitatory reflexes. NO, specifically nNOS mediates sympathetic cardiac-cardiovascular responses through its action in the rVLM.[23]

Acupuncture stimulation increases blood flow of the stimulated area by causing axon reflex and increased cardiac output. [24] and regulate the cardiovascular system.

\subsection{Blood flow distributing among different vascular beds are regulated by changes of vascular tone via controlled NO processing}

Mechanical forces, comprising both unidirectional laminar and oscillatory shear, induce an increase in NO production through increased activation and expression of eNOS. The nNOS and eNOS have distinct local roles in the physiologic regulation of human coronary and peripheral microvascular tone in vivo. Whereas eNOS-generated NO facilitates dynamic alterations in blood flow distribution, the tonic generation of $\mathrm{NO}$ by $\mathrm{nNOS}$ may be important for the regulation of basal vasomotor tone and blood flow $[25,26]$.

Hemoglobin, albumin, and glutathione carry and release nitric oxide (NO) within microvessels. NO moves in blood vessels from upstream to downstream resistance vessels which allow larger vessels that generate large $\mathrm{NO}$ to influence vascular tone in downstream vessels in response to both flow and receptor stimuli [27].

When acupunctured at a specific acupuncture point, the local mechanical stress produced is coupled with a cyclic strain of blood vessel and changes the resonance frequency of arterial trees [28]. Vascular blood flow and its distribution among different vascular beds are regulated by changes in microvascular tone.

\section{Evaluation of the proposed blood flow modulation model}

Traditional acupuncture theory proposes that the needling of appropriately selected acupuncture points has effects that are remote from the site of needle insertion, and this is mediated by means of the meridian system [29]. To date, physiological models attempting to 
explain these remote effects have either invoked systemic mechanisms involving the nervous system, or involved signal transduction through connective tissue combining with the involvement of other systems including the nervous system [30,31].

It has been found that the mean of laser Doppler flowmetry (LDF) signals were significantly larger at the acupoints than in their surrounding tissues, which indicated a large volume of blood delivery to the microvascular beds of acupoints. These results indicate that the physical properties of the vascular structure of acupoints may affect the perfusion resistance, and modulate the microcirculatory perfusion [32].

\subsection{Mechanotransduction between the acupuncture point and connective tissue}

In order to understand the acupoint/meridian system, all the studies were mainly looked for distinct histological features that might differentiate acupuncture points from the surrounding tissue for past 30 years.

Various structures, such as neurovascular bundles [33-36], neuromuscular attachments [3739] and various types of sensory nerve endings [37, 40, 41-45], have been described at acupoints. Nevertheless, acupoints and meridians are frequently located along connective tissue planes, that is between muscles or between muscle and bone or tendon[46-48].

When needles were inserted into acupoints, the connective tissue around the acupuncture needle is wounded. This allows the needle is able to pull and distort the surrounding tissue and this movement delivers a mechanical signal into the tissue at the cellular level $[49,50]$. Such mechanical signals are recognized as important mediators of information at the cellular level [51] and could be transduced into bioelectrical and/or biochemical signals $[52,53]$ and lead to downstream effects, including cellular actin cytoskeleton polymerization, signaling pathway activation, changes in gene expression, protein synthesis and extracellular matrix modification [54,55].

It has been suggested that the mechanism underlying needle grasp in acupuncture is caused by the muscle contraction $[57,58]$. Since neurovascular bundles are located along connective tissue planes, the same amount of needle grasp may have more powerful downstream effects at acupoints due to the mechanical matrix deformation caused by tissue winding. Acupuncture has been shown to improve cutaneous microcirculation and tissue healing in musculoskeletal flaps in rats $[59,60]$ and to increase circulation in the skin above the parotid glands [61]. Mechanical forces are also able to initiate complex signal transduction cascades, including the nuclear factor-kappaB and mitogen-activated protein kinase pathways and these lead to functional changes within the cell [62].

\subsection{Mechanical force modulates NO production, and mediates the local vascular circulation}

Changes in ECM composition can modulate the transduction of mechanical signals to, between and within cells [56]. Acupuncture needle manipulation, thus, may cause lasting modification of the ECM surrounding the needle, which may, in turn, influence the various cell populations sharing this connective tissue matrix such as fibroblasts, sensory afferents, immune and vascular cells. Vascular cells are equipped with numerous receptors that allow them to detect and respond to the mechanical forces generated by pressure and shear stress. The cytoskeleton and other structural components have an established role in mechanotransduction and are able to transmit and modulate tension within the cell via focal adhesion sites, integrins, cellular junctions and the ECM. 
Traditionally, eNOS, which is primarily a membrane-bound protein [69], is considered the principal source of bio-available vascular NO. In recent years, the role of nNOS-generated $\mathrm{NO}$ in vascular function has been clearly demonstrated [63-68]. Several studies [73, 74] reported that nNOS-containing nerve fibers, which innervate arterioles and nerve terminals, are the major sources of arteriolar NO. The availability of NO in arteriolar endothelium and mast cells appeared to be maintained mainly by nNOS, whereas that in venular endothelium greatly depends on eNOS.

Through the ECM, the mechanical force stimulus can travel across the acupoint into the local tissue cells including arterioles, nerve terminals and mast cells, and this will trigger nNOS induced NO production [9] which diffuses into the vascular smooth muscle and change blood flow and local circulation.

\subsection{Acupuncture regulates central cardiovascular activities by NO production}

When acupuncture stimulates forelimb, hindlimb, chest, and abdomen of human body, all the heart rate of above parts decreases significantly which were paralleled by the decreasing in cardiac sympathetic nerve activity. The reflex pathway to decrease heart rate by acupuncture-like stimulation consists of mainly group IV muscle afferent fibers whose activity leads to the activation of GABA-ergic neurons in the brainstem and an inhibition of sympathetic outflow to the heart [93].

When electro-acupuncture applied on the acupoint ST-36, the functional magnetic resonance imaging (fMRI) activity in the hypothalamus, the dorsal raphe nucleus, the periaqueductal gray, and the rVLM showed significant correlation with the heart rate variability (HRV) data [94]. EA at acupoints overlying deep and superficial somatic nerves leads to point-specific effects on cardiovascular reflex responses. Sympathetic cardiovascular rVLM neurons that respond to both visceral (reflex) and somatic (EA) nerve stimulation manifest different level of responses during stimulation of specific acupoints [22]. Acupuncture stimulation seems to reduce sympathetic nervous system activation via activating of the cholinergic system or opioid receptors in the rVLM [4,39]. Nitric oxide (NO) synthase (NOS)-containing neurons in the rVLM are activated during cardiac sympathoexcitatory reflexes. NO, specifically nNOS mediates sympathetic cardiac-cardiovascular responses through its action in the rVLM [23].

Acupuncture stimulation increases the blood flow of the stimulated area by causing axon reflex and increased cardiac output, as well as a decrease in total peripheral resistance via CNS at the same time [24].

\subsection{Blood flow distribution among different vascular beds is regulated by changes in vascular tone via controlled NO processing.}

The organ blood flow affected differently by stimulating different points, and different methods or regions of acupuncture stimulation also influence blood pressure and autonomic nerves differently [24]. The functional magnetic resonance imaging (fMRI) studies have shown that acupuncture stimulation, when associated with sensations comprising deqi, evokes deactivation of a limbic-paralimbic-neocortical network, which encompasses the limbic system, as well as activation of somatosensory brain regions [97,98]. Among acupuncture-like stimuli delivered to the body, cortical cerebral blood flow was increased by stimuli to face (brain stem), forepaw (the spinal cord at cervical) and hindpaw (the spinal cord at cervical). The afferent pathway of the responses is composed of somatic groups III 
and IV afferent nerves and whose efferent nerve pathway includes intrinsic cholinergic vasodilators originating in the basal forebrain [99]. Activation of parasympathetic nitrergic nerves innervating renal vasculature contributes to vasodilatation in renal arteries and preand postglomerular arterioles, an increase in renal blood flow. NO from neurons in the brain acts on the paraventricular nucleus of the hypothalamus and the rVLM and inhibits the central sympathetic nerve activity to the kidney, leading to renal vasodilatation and increased renal blood flow [100].

In a knee joint microcirculation study, a dynamic balance between the autonomic nervous system and the release of NO is the primary mechanism mediating the electro-acupuncture stimulation (EAS) effects has been suggested [95]. When acupuncture was given at ST36 of rat, the blood perfusion in the stomach increased significantly, the blood perfusion in the blood vessels and microcirculation of other body parts significantly increased. [96]

Generation of free NO from nonenzymatic reservoir in circulation including S-nitrosothiols and hemoglobin $(\mathrm{Hb})$ has been recognized as a major physiological source of NO in biological systems including vasculature [70-72].

NO is produced by endothelial cells and diffuses into vascular smooth muscle and into the flowing blood, where it rapidly reacts with $\mathrm{Hb}$ in red blood cells (RBC). $\mathrm{RBC}$ has an active nitric oxide synthesizing mechanism which has properties similar to eNOS syntheses. This RBC-NOS activity contributes to the NO export from RBC. RBC-NO generating mechanisms can be stimulated by exposing red cells to shear stress and that calcium plays a role in this stimulation [73].

Mechanical forces, comprising both unidirectional laminar and oscillatory shear, are being recognized as important inducers of vascular NO generation. Laminar shear induces an increase in NO production through increased activation and expression of eNOS. Precisely, laminar shear activates eNOS through both Ca2+-dependent and Ca2+-independent mechanisms $[74,75]$. Oscillatory shear has also been shown to be able to stimulate an acute increase in NO production and up-regulation of eNOS [76]. Periodic bursts of intracellular free $\mathrm{Ca}^{2+}$ in response to a constant agonist concentration have been observed in a number of non-excitable cell types including endothelial cells [77-79]. There is controversy regarding shear stress-induced $\mathrm{Ca}^{2+}$ transient release in endothelial cells with some investigators reporting multiple $\mathrm{Ca}^{2+}$ transient events [80-83], whereas others report only their irregular appearance or nothing at all [84-86]. Furthermore, both transient and sustained release of NO has been reported in response to this shear stress. It is seems that shear stress regulates NO release in a $\mathrm{Ca}^{2+}$-independent mode through phosporylation of eNOS, which results in a sustained basal NO production irrespective of the presence or absence of the $\mathrm{Ca}^{2+}$ transient effect [87-89]. Kutchan and Frangos [90] measured the NO end-oxidation products $\left(\mathrm{NO}_{2}^{-}\right.$and $\left.\mathrm{NO}_{3}^{-}\right)$released from endothelial cells exposed to laminar flow and reported the presence of transient $\mathrm{Ca}^{2+}$-dependent $\mathrm{NO}$ release at the initial moment but sustained release in the presence of a constant shear stress level. Buerk and Riva [91] observed the presence of spontaneous low-frequency NO oscillations in the cat optic nerve head, which were attributed to a natural variation in shear stress. Kanai et al. [92] measured NO release from endothelial cells exposed to constant shear stress using of NO-sensitive microelectrodes and reported shear stress induced periodic $\mathrm{Ca}^{2+}$ transient release and a concomitant release of $\mathrm{NO}$.

Several studies have indicated nNOS to be present in perivascular nerve fibers [101]. Vascular blood flow and its distribution among different vascular beds are regulated by 
changes in microvascular tone. NO plays a key role in the local paracrine regulation of vessel tone both under resting conditions and when blood flow increases in response to agonist stimulation or increased shear stress. The nNOS plays an important role in the local regulation of vessel tone, independent of the effects of nNOS-derived NO in the central nervous system [28]. The nNOS and eNOS have distinct local roles in the physiologic regulation of human coronary and peripheral microvascular tone in vivo and then, that these isoforms may therefore subserve distinct functions. Whereas eNOS-generated NO facilitates dynamic alterations in blood flow distribution, the tonic generation of NO by nNOS may be important for the regulation of basal vasomotor tone and blood flow $[25,26]$. If Blood vessels are continuously subjected to mechanical forces in the form of stretching and this encompasses cyclic mechanical strain due to the pulsatile nature of blood flow and shear stress. These are accompanied by phenotypical modulation of smooth muscle cells and endothelial cells, which then produce structural modifications of the arterial wall. The hemoglobin, albumin, and glutathione carry and release NO may have influenced the movement of $\mathrm{NO}$ by blood within microvessels. NO can move in blood from upstream to downstream resistance vessels. This mechanism allows larger vessels that generate large amount of NO to influence vascular tone in downstream vessels in response to both flow and receptor stimuli [27].

A meridian is a hypothetical or functional line linking various arterial trees (acupuncture points) that have a similar resonance property [28]. The meridian selected frequency may be the same as the resonant frequency of its related internal organ. From the pressure wave propagation equation, the resonance frequency of the organs (or tissue's) main artery coupled system will decide the blood pressure energy distribution. Needling at an acupoints is a disturbance that will cause an impedance mismatch and therefore influence the efficiency of the resonance. Stimulating an acupuncture point, which is a tissue-rich with small arteries, is an effective way to cause the redistribution of blood pressure energy and therefore influence the blood perfusion.

From above studies, it is suggested that when acupuncture is applied at a specific acupoint, the local mechanical stress produced from needle grasp is able to trigger a burst of NO production and couple with the cyclic strain of the blood vessels, then there is a change in the microvascular tone of blood vessels. NO in the central nervous system plays a very important role in the control of sympathetic outflow and regulation of cardiovascular activities. This has exerted an effect on the artery tree changing the various meridian organs' blood distribution and perfusion in our body. The mechanism underlying the increased blood flow resulting from acupuncture rely on the activation of thin nerve fibers and these release vasoactive neuropeptides and NO from their peripheral terminals upon activation. A dynamic balance between the autonomic nervous system and the release of NO is the primary mechanism mediating the acupuncture stimulation effects in the local microcirculation.

\section{Discussion}

Acupuncture has been shown to improve cutaneous microcirculation and tissue healing in musculoskeletal flaps in rats $[59,60]$ and to increase circulation in the skin above the parotid glands [61]. The mechanism underlying increased blood flow by acupuncture has been suggested to rely on the activation of thin nerve fibers, which release vasoactive 
neuropeptides and NO from their peripheral terminals upon activation; this leads to vasodilatation and increased blood flow $[1,102,103]$. It is noted that because NO is involved in multiple body functions, its presence in the peripheral blood or in an acupuncture point is supportive of our hypothesis.

According to Traditional Chinese Medical theory, acupuncture points are functionally related to certain visceral organs and these relationships have been partially proved by clinical application of acupuncture therapy. Acupuncture point ST36 (stomach 36) is the most commonly used acupuncture point for the purpose of immune strengthening and immune regulation in oriental medical clinics (specifically strengthening and regulating Qi and blood in oriental medical terminology) [104]. Lee's morphological study [105] suggest that there is a commonality of CNS cell groups in brain controlling the stomach (viscera) and the Zusanli point (ST36). A fMRI study was able to demonstrate that stimulation of ST36/SP6 specifically activated the orbital frontal cortex and de-activated the hippocampus [106]. Alternatively, stimulation of GB34/BL57 activated the dorsal thalamus and inhibited various primary motor areas and the premotor cortex. These results strongly support the existence of acupoint specificity.

The modulatory effect of acupuncture on the cardiovascular and the sympathetic system has been referred to somatoautonomic reflexes [107]. Manual acupuncture stimulation elicited a transient increase similar to skin sympathetic nerve activity (SSNA) and that this increase is dependent on the baseline of the SSNA [108]. EA can reduce sympathetic nerve activity (SNA) and arterial pressure (AP). Specifically, short-term EAe of ST36 is able to resets the neural arc to a lower SNA, which moves the operating point toward lower AP and SNA under baroreflex closed-loop conditions [109]. L-arginine-derived NO synthesis appears to mediate noradrenergic function during skin sympathetic nerve activation, which probably contributes to skin electrical resistance of the acupuncture points and meridians [10].

It has been speculated that acupuncture stimulates some sensory nerves or the autonomic nervous system and induces the recovery of blood circulation [110-112]. NO content and nNOS expression have been shown to be consistently higher at the skin acupuncture points/meridians [9]. EA at ST-36 is regulated through NOS in those organs on the stomach meridians [8]. ST-36 is used to promote blood flow and to treat cardiovascular disease; therefore, ST-36 possibly induces its beneficial antihypertensive effect by activating NOS in the microcirculation. Meanwhile, acupuncturing ST-36 alone has been shown to produce different results when used to treat a renal hypertensive hamster compared to a shamoperated hamster. However, this is not universal for all acupoints and there was no response in organs that are not responsible for hypertension illness.

According Traditional Chinese Medical theory, the effects of acupuncture at a specific point are expressed differently. Here, a blood-flow modulation model starting from a local perspective was proposed and this model is able to suggest physiological processes that can bridge from the traditional nerve model of acupuncture to the vascular model. Based on this, we suggest that when target organs located on and not located on the same meridian as, for example, ST-36, it should be possible to identify the physiological mechanisms responsible for individual organ behavior. However, while acupuncturing ST-36 alone has produced different results between renal hypertensive hamster and sham-operated control [8], there is also need to consider differences in the operation methods. Finally, we suggest that the best approach to a physiological study of acupuncture point either alone or combined with other acupuncture points should involve a broad range of measurements in addition to studying NOS. 
The Traditional Chinese medical theory says: 'Qi acts as the commander of blood , and blood acts as the mother of Qi' This is a general description of the effects of Qi on blood and it can be expanded to include the ideas that Qi promotes blood production, and controls the blood circulation. Furthermore blood conveying Qi and blood nourishing Qi. If we suppose the NO is Qi, then the model we propose can be annotated as this part of Traditional Chinese Medical theory.

\section{Acknowledgements}

We thank Dr WF Hsiao's comment for this manuscript.

\section{References}

[1] Sandberg M, Lundeberg T, Lindberg LG, Gerdle B. Effects of acupuncture on skin and muscle blood flow in healthy subjects. Eur J Appl Physiol. 2003; 90: 114-119.

[2] Johng HM, Cho JH, Shin HS. Frequency dependence of impedances at the acupuncture point Quze (PC3). IEEE Eng Med Biol Mag. 2002; 21: 33-36.

[3] Lee MS, Jeong SY, Lee YH, Jeong DM, Eo YG, Ko SB Differenences in electrical conduction properties between meridians and non-meridians. Am J Chin Med. 2005; 33(5): 723-728.

[4] Langevin HM, and Yandow JA. Relationship of acupuncture points and meridians to connective tissue planes. Anat Rec. 2002; 269: 257-265.

[5] Ma W, Tong H, Xu W. Perivascular space: possible anatomical substrate for the meridian. J Altern Complement Med. 2003; 9: 851-859.

[6] Ma SX. Neurobiology of Acupuncture: Toward CAM. Evid Based Complement Alternat Med. 2004; 1: 41-47.

[7] Tsuchiya M, Sato EF, Inoue M, Asada A. Acupuncture enhances generation of nitric oxide and increases local circulation. Anesth Analg. 2007; 104: 301-307.

[8] Kim DD, Pica AM, Duran RG, Duran WN. Acupuncture reduces experimental renovascular hypertension through mechanisms involving nitric oxide synthases. Microcirculation. 2006; 13: 577-585.

[9] Ma SX. Enhanced nitric oxide concentrations and expression of nitric oxide synthase in acupuncture points/meridians. J Altern Complement Med. 2003; 9: 207-215.

[10] Chen JX, and Ma SX. Effects of nitric oxide and noradrenergic function on skin electric resistance of acupoints and meridians. J Altern Complement Med. 2005; 11: 423-431.

[11] Greener M. Now You're signaling, with gas. The Scientist. 2004; 18:17. http://www.thescientist.com/yr2004/sep/research_040913.html

[12] Lowenstein CJ, and Padalko E. iNOS (NOS2) at a glance. J Cell Sci. 2004; 117: 2865-2867.

[13] Alderton WK, Cooper CE, Knowles RG. Nitric oxide synthases: structure, function and inhibition. Biochem J. 2001; 357: 593-615.

[14] Li H, Wallerath T, Forstermann U. Physiological mechanisms regulating the expression of endothelial-type NO synthase. Nitric Oxide. 2002; 7: 132-147.

[15] Siervo M, Capuano L, Colantuoni A. Physiology and in vivo measurements of nitric oxide in man. Clin Ter. 2010; 161(2): 173-183.

[16] Kara T, Narkiewicz K, Somers VK. Chemoreflexes--physiology and clinical implications. Acta Physiol Scand. 2003; 177: 377-384. 
[17] Schmetterer L, Findl O, Strenn K. Role of NO in the O2 and CO2 responsiveness of cerebral and ocular circulation in humans. Am J Physiol. 1997; 273(6 Pt 2): R2005R2012.

[18] Wang, Q., O. B. Paulsen, N. A. Lassen. Effect of nitric oxide blockade by NG-nitro-Larginine on cerebral blood flow response to changes in carbon dioxide tension. $J$. Cereb. Blood Flow Metab. 1992; 12: 935-946.

[19] Kavdia M, and Popel AS. Contribution of nNOS- and eNOS-derived NO to microvascular smooth muscle NO exposure. J Appl Physiol. 2004; 97: 293-301.

[20] Chiquet M, Matthisson M, Koch M, Tannheimer M, Chiquet-Ehrismann R. Regulation of extracellular matrix synthesis by mechanical stress. Biochem Cell Biol. 1996; 74: 737-744.

[21] Silver FH, and Siperko LM. Mechanosensing and mechanochemical transduction: how is mechanical energy sensed and converted into chemical energy in an extracellular matrix? Crit Rev Biomed Eng. 2003; 31: 255-331.

[22] Tjen-A-Looi SC, Li P, Longhurst JC. Medullary substrate and differential cardiovascular responses during stimulation of specific acupoints. Am J Physiol Regul Integr Comp Physiol. 2004; 287(4): R852-R8562.

[23] Guo ZL, Tjen-A-Looi SC, Fu LW, Longhurst JC. Nitric oxide in rostral ventrolateral medulla regulates cardiac-sympathetic reflexes: role of synthase isoforms. Am J. Physiol Heart Circ Physiol. 297(4): H1478-H1486.

[24] Tsuru H, and Kawakita K. Acupuncture on the blood flow of various organs measured simultaneously by colored microspheres in rats. Evid Based Complement Alternat Med. 2009; 6(1): 77-83.

[25] Seddon M, Melikian N, Dworakowski R, Shabeeh H, Jiang B, Byrne J, Casadei B, Chowienczyk P, Shah AM. Effects of neuronal nitric oxide synthase on human coronary artery diameter and blood flow in vivo. Circulation. 2009; 119(20): 26562662.

[26] Melikian N, Seddon MD, Casadei B, Chowienczyk PJ, Shah AM. Neuronal nitric oxide synthase and human vascular regulation. Trends Cardiovasc Med. 2009 ; 19(8): 256262.

[27] Bohlen HG, Zhou X, Unthank JL, Miller SJ, Bills R. Transfer of nitric oxide by blood from upstream to downstream resistance vessels causesmicrovascular dilation. Am J Physiol Heart Circ Physiol. 2009; 297(4): H1337-H1346.

[28] Wan WK, Hsu TL, Chang HC, Wan YY. Effect of acupuncture at Hsien-Ku (St-43) on the pulse spectrum and a discussion of the evidence for the frequency structure of Chinese medicine. Am J Chin Med. 2000; 28: 41-55.

[29] O'Connor J, and Bensky D. Acupuncture, a comprehensive text (Shanghai College of Traditional Medicine) Seattle: Eastland Press, (1981).

[30] Ulett GA, Han S, Han JS. Electroacupuncture: mechanisms and clinical applications. Biol Psych. 1998; 44: 129-138.

[31] Pomeranz B. Acupuncture analgesia-basic research. In: Stux G, Hammerschlag R, editors. Clinical acupuncture-scientific basis. Berlin: Springer-Verlag (2001).

[32] Hsiu H, Huang SM, Chao PT, Jan MY, Hsu TL, Wang WK, Wang YY. Microcirculatory characteristics of acupuncture points obtained by laser Doppler flowmetry. Physiol Meas. 2007; 28(10): N77-N86.

[33] Rabischong P, Niboyet JEH, Terral C, Senelar R, Casez R. Bases experimentales de l'analgesie acupuncturale. Nouv Presse Med. 1975; 4: 2021-2026. 
[34] Senelar R. Les characteristiquesmorphologiques des points chinois. In: Niboyet JEH, editor. Nouveau traited'acupuncture. Paris: Maisonneuve (1979).

[35] Bossy J. Morphological data concerning the acupuncture points and channel network. Acupunct Electrother Res. 1984; 9: 79-106.

[36] Rabischong P, Niboyet JEH, Terral C, Senelar R, Casez R. Bases experimentales de l'analgesie acupuncturale. Nouv Presse Med. 1975; 4: 2021-2026.

[37] Liu KY, Varela M, Oswald R. The correspondence between some motor points and acupuncture loci. Am J Chin Med. 1975; 3: 347-358.

[38] Gunn CC, Ditchburn FG, King MH, Renwick GJ. Acupuncture loci: A proposal for their classification according to their relationship to known neural structures. Am J Chin Med. 1976; 4: 183-195.

[39] Dung HC. Anatomical features contributing to the formation of acupuncture points. Am J Acupunct. 1984; 12: 139-143.

[40] Shanghai Medical University, Human Anatomy Department. A relationship between points of meridians and peripheral nerves: Acupuncture anaesthetic theory study. Shanghai: People's Republic Publishing House (1973).

[41] Ciczek LSW, Szopinski J, Skrzypulec V. Investigations of morphological structures of acupuncture points and meridians. J Trad Chin Med. 1985; 5: 289-292.

[42] Dung, HC. Anatomical features contributing to the formation of acupuncture points. Am J Acup. 1984; 12: 139-143.

[43] Gunn, CC, Ditchburn FG, King MH, Renwick GJ. Acupuncture loci: a proposal for their classification according to their relationship to known neural structures. Am J Chin Med. 1976; 4: 183-195.

[44] Ifrim-Chen and Ifrim, M. Acupoints [corrected] and meridians: a histochemical study. Ital J Anat Embryol. 2005; 110: 51-57.

[45] Li AH, Zhang JM, Xie YK. Human acupuncture points mapped in rats are associated with excitable muscle/skin-nerve complexes with enriched nerve endings. Brain Res. 2004; 1012: 154-159.

[46] Cheng X. Chinese Acupuncture and Moxibustion. Beijing, China: Foreign Language Press (1987).

[47] Stux G, and Pomeranz B. Acupuncture textbook and atlas. Berlin: Springer-Verlag (1987).

[48] Worsley JR. Traditional Chinese Acupuncture Volume 1: Meridians and Points. Tisbury: Element Books (1982).

[49] Langevin HM, Churchill DL, Wu J. Evidence of connective tissue involvement in acupuncture. FASEB J. 2002; 16: 872-874.

[50] Langevin HM, Churchill DL, Cipolla MJ. Mechanical signaling through connective tissue: A mechanism for the therapeutic effect of acupuncture. FASEB J. 2001; 15: 2275-2282.

[51] Giancotti FG, and Ruoslahti E. Integrin signaling. Science 1999; 285: 1028-1032.

[52] Banes AJ, Tsuzaki M, Yamamoto J. Mechanoreception at the cellular level: The detection, interpretation and diversity of responses to mechanical signals. Biochem Cell Biol. 1995; 73: 349-365.

[53] Lai WM, Mow VC, Sun DD, Atesian GA. On the electric potentials inside a charged soft hydrated biological tissue: Streaming potential versus diffusion potential. J Biomech Eng. 2000; 122: 336-346.

[54] Chicurel ME, Chen CS, Ingber DE. Cellular control lies in the balance of forces. Curr Opin Cell Biol. 1998; 10: 232-239. 
[55] Chiquet M. Regulation of extracellular matrix gene expression by mechanical stress. Matrix Biol. 1999; 18: 417-426.

[56] Brand RA. What do tissues and cells know of mechanics? Ann Med 1997; 29: 267-269.

[57] Gunn, CC, and Milbrandt WE. The neurological mechanism of needle grasp in acupuncture. Am J Acup. 1977; 5: 115-120.

[58] Stux G, and Pomeranz B. Basics of Acupuncture (3rd ed.). Berlin: Springer-Verlag, (1995).

[59] Jansen G, Lundeberg T, Kjartansson J, Samuelson UE. Acupuncture and sensory neuropeptides increase cutaneous blood flow in rats. Neurosci Lett. 1989; 97: 305309.

[60] Jansen G, Lundeberg T, Samuelson UE, Thomas M. Increased survival of ischaemic musculocutaneous flaps in rats after acupuncture. Acta Physiol Scand. 1989; 135: 555558.

[61] Blom M, Lundeberg T, DawidsonI, Angmar-Mansson B. Effects on local blood flux of acupuncture stimulation used to treat xerostomia in patients suffering from Sjogren's syndrome. J Oral Rehabil. 1993; 20: 541-548.

[62] Lehoux S, Castier Y, Tedgui A. Molecular mechanisms of the vascular responses to hemodynamic forces. J Intern Med. 2006; 259: 381-392.

[63] Boulanger CM, Heymes C, Benessiano J, Geske RS, Levy BI, Vanhoutte PM. Neuronal nitric oxide synthase is expressed in rat vascular smooth muscle cells: activation by angiotensin II in hypertension. Circ Res. 1998; 83: 1271-1278.

[64 ] Ichihara A, Inscho EW, Imig JD, Navar LG. Neuronal nitric oxide synthase modulates rat renal microvascular function. Am J Physiol Renal Physiol. 1998; 274: F516-F524.

[65] Toda N, and Okamura T. The pharmacology of nitric oxide in the peripheral nervous system of blood vessels. Pharmacol Rev. 2003; 55: 271-324.

[66] Gocan NC, Scott JA, Tyml K. Nitric oxide produced via neuronal NOS may impair vasodilatation in septic rat skeletal muscle. Am J Physiol Heart Circ Physiol. 2000; 278: H1480-H1489.

[67 ] Ren YL, Garvin JL, Ito S, Carretero OA. Role of neuronal nitric oxide synthase in the macula densa. Kidney Int. 2001; 60: 1676-1683.

[68 ] Tong XK, and Hamel E. Basal forebrain nitric oxide synthase (NOS)-containing neurons project to microvessels and NOS neurons in the rat neocortex: cellular basis for cortical blood flow regulation. Eur J Neurosci. 2000; 12: 2769-2780.

[69] Griffith OW, and Stuehr DJ. Nitric oxide synthases: properties and catalytic mechanism. Annu Rev Physiol. 1995; 7: 707-736.

[70] Stamler JS, Jia L, Eu JP, McMahon TJ, Demchenko IT, Bonaventura J, Gernert K, Piantadosi CA. Blood flow regulation by $S$-nitrosohemoglobin in the physiological oxygen gradient. Science. 1997; 276: 2034-2037.

[71] Pawloski JR, Hess DT, Stamler JS. Export by red blood cells of nitric oxide bioactivity. Nature. 2001; 409: 622-626.

[72] Gow AJ, Chen Q, Hess DT, Day BJ, Ischiropoulos H, Stamler JS. Basal and stimulated protein S-nitrosylation in multiple cell types and tissues. J Biol Chem. 2002; 277: 9637-9640.

[73] Ulker P, Meiselman HJ, Baskurt OK. Nitric oxide generation in red blood cells induced by mechanical stress. Clin Hemorheol Microcirc. 2010; 45(2-4): 169-175.

[74] Corson MA., James NL. Latta SE. Phosphorylation of endothelial nitric oxide synthase in response to fluid shear stress. Circ Res 1996; 79: 984-991. 
[75] Boo YC, and Jo H. Flow-dependent regulation of endothelial nitric oxide synthase: role of protein kinases. Am J Physiol Cell Physiol. 2003; 285: C499-C508.

[76] Cai H, McNally JS, Weber M, Harrison DG.. Oscillatory shear stress upregulation of endothelial nitric oxide synthase requires intracellular hydrogen peroxide and CaMKII. J Mol Cell Cardiol. 2004; 37: 121-125.

[77] Berridge MJ. Calciumoscillations. J Biol Chem. 1990; 265: 583-9586.

[78] Lauffenburger DA, and Linderman JL. Receptors, models for binding, Trafficking, and Signaling. New York: Oxford Univ. Press (1993).

[79] Meyer T, and Stryer L. Calcium spiking. Annu Rev BiophysBiophys Chem. 1991; 20: 153-174.

[80] Helmlinger G, Berk BC, Nerem RM. Pulsatile and steady flow-induced calcium oscillations in single cultured endothelial cells. J Vasc Res. 1996; 33: 360-369.

[81] Hoyer J, Kohler R, Distler A. Mechanosensitive $\mathrm{Ca}^{2+}$ oscillations and STOC activation in endothelial cells. FASEB J. 1998; 12:359-366.

[82] Schwarz G, Callewaert G, Droogmans G, Nilius B. Shear stress-induced calcium transients in endothelial cells from human umbilical cord veins. J Physiol. 1992; 458: 527-538.

[83] Shen J, Luscinskas FW, Connolly A, Dewey CF, Jr. Gimbrone MA Jr. Fluid shear stress modulates cytosolic free calcium in vascular endothelial cells. Am J Physiol Cell Physiol. 1992; 262: C384-C390.

[84] Dull RO, Davies PF. Flow modulation of agonist (ATP)-response $\left(\mathrm{Ca}^{2+}\right)$ coupling in vascular endothelial cells. Am J Physiol Heart Circ Physiol. 1991; 261: H149-H154.

[85] Mo M, Eskin SG, Schilling WP. Flow-induced changes in $\mathrm{Ca}^{2+}$ signaling of vascular endothelial cells: effect of shear stress and ATP. Am J Physiol Heart Circ Physiol. 1991; 260: H1698-H1707.

[86] Schilling WP, Mo M, Eskin SG. Effect of shear stress on cytosolic $\mathrm{Ca}^{2+}$ of calf pulmonary artery endothelial cells. Exp Cell Res. 1992; 198: 31-35.

[87] Ayajiki K, Kindermann M, Hecker M, Fleming I, Busse R. Intracellular pH and tyrosine phosphorylation but not calcium determine shear stress-induced nitric oxide production in native endothelial cells. Circ Res. 1996; 78: 750-758.

[88] Boo YC, Sorescu G, Boyd N. Shear stress stimulates phosphorylation of endothelial nitric-oxide synthase at Ser1179 by Akt-independent mechanisms: role of protein kinase A. J Biol Chem. 2002; 277: 3388-3396.

[89] Fleming I, and Busse R. Molecular mechanisms involved in the regulation of the endothelial nitric oxide synthase. Am J Physiol Regul Integr Comp Physiol. 2003; 284: R1-R12.

[90] Kuchan MJ, and Frangos JA. Role of calcium and calmodulin in flow-induced nitric oxide production in endothelial cells. Am J Physiol Cell Physiol. 1994; 266: C628-C636.

[91] Buerk DG, and Riva CE. Vasomotion and spontaneous low-frequency oscillations in blood flow and nitric oxide in cat optic nerve head. Microvasc Res. 1998; 55: 103-112.

[92] Kanai AJ, Strauss HC, Truskey GA, Crews AL, Grunfeld S, Malinski T. Shear stress induces ATP-independent transient nitric oxide release from vascular endothelial cells, measured directly with a porphyrinic microsensor. Circ Res. 1995; 77: 284-293.

[93] Uchida S, Kagitani F, Hotta H. Mechanism of the reflex inhibition of heart rate elicited by acupuncture-like stimulation in anesthetized rats. Auton Neurosci. 2008; 143(12): $12-19$.

[94] Napadow V, Dhond RP, Purdon P, Kettner N, Makris N, Kwong KK, Hui KK. Correlating acupuncture FMRI in the human brainstem with heart rate variability. Conf Proc IEEE Eng Med Biol Soc. 2005; 5: 4496-4499. 
[95] Loaiza LA, Yamaguchi S, Ito M, Ohshima N. Electro-acupuncture stimulation to muscle afferents in anesthetized rats modulates the blood flow to the knee joint through autonomic reflexes and nitric oxide. Auton Neurosci. 2002; 97(2): 103-109.

[96] Dong Z, Shun-Yue L, Shu-You W, Hui-Min M. Evaluation of influence of acupuncture and electro-acupuncture for blood perfusion of stomach by Laser Doppler Blood Perfusion Imaging. Evid Based Complement Alternat Med. 2011.

[97] Hui KK, Marina O, Liu J, Rosen BR, Kwong KK. Acupuncture, the limbic system, and the anticorrelated networks of the brain. Auton Neurosci. 2010; 157(1-2): 81-90.

[98] Fang J, Jin Z, Wang Y, Li K, Kong J, Nixon EE, Zeng Y, Ren Y, Tong H, Wang Y, Wang $P$, Hui KK. The salient characteristics of the central effects of acupuncture needling: limbic-paralimbic-neocortical network modulation. Hum Brain Mapp. 2009; 30(4): 1196-1206.

[ 99] Uchida S, and Hotta H. Acupuncture affects regional blood flow in various organs. Evid Based Complement Alternat Med. 2008; 5(2): 145-151.

[100] Toda N, and Okamura T. Modulation of renal blood flow and vascular tone by neuronal nitric oxide synthase-derived nitric oxide. J Vasc Res. 2011; 48(1): 1-10.

[101] Nozaki K, Moskowitz MA, Maynard KI. Possible origins and distribution of immunoreactive nitric oxide synthase-containing nerve fibers in cerebral arteries. $J$ Cereb Blood Flow Metab. 1993; 13: 70-79.

[102] Jänig W, and Lisney SJ. Small diameter myelinated afferents produce vasodilatation but not plasma extravasation in rat skin. J Physiol. 1989; 415: 477-486.

[103] Kashiba H, and Ueda Y. Acupuncture to the skin induces release of substance P and calcitonin gene-related peptide from peripheral terminals of primary sensory neurons in the rat. Am J Chin Med. 1991; 19: 189-197.

[104] Lade A. Acupuncture points images and functions. Eastland press, Washington (1989).

[105] Lee CH, Jung HS, Lee TY. Studies of the central neural pathways to the stomach and Zusanli (ST36). Am J Chin Med. 2001; 29: 211-220.

[106] Zhang WT, Jin Z, Luo F, Zhang L, Zeng YW, Han JS. Evidence from brain imaging with fMRI supporting functional specificity of acupoints in humans. Neurosci Lett. 2004; 354: 50-53.

[107] Budgell, B., and Sato A. Modulations of autonomic functions by somatic nociceptive inputs. Neurosci Lett. 1996; 113: 525-539.

[108] Kimura K, Masuda K, Wakayama I. Changes in skin blood flow and skin sympathetic nerve activity in response to manual acupuncture stimulation in humans. Am J Chin Med. 2006; 34: 189-196.

[109] Michikami D, Kamiya A, Kawada T. Short-term electroacupuncture at Zusanli resets the arterial baroreflex neural arc toward lower sympathetic nerve activity. Am J Physiol Heart Circ Physiol. 2006; 291: H318-H326.

[110] Nishijo K., Mori H., Yosikawa K,Yazawa K. Decreased heart rate by acupuncture stimulation in humans via facilitation of cardiac vagal activity and suppression of cardiac sympathetic nerve. Neurosci Lett. 1997; 227: 165-168.

[111] Tam KC, and Yiu HH. The effect of acupuncture on essential hypertension. Am. J. Chin. Med. 1975; 3: 369-375.

[112] Williams T, Mueller K, Cornwall MW. Effect of acupuncture - point stimulation on diastolic blood pressure in hypertensive subjects: a preliminary study. Phys. Ther. 1991; 71: 523-529. 


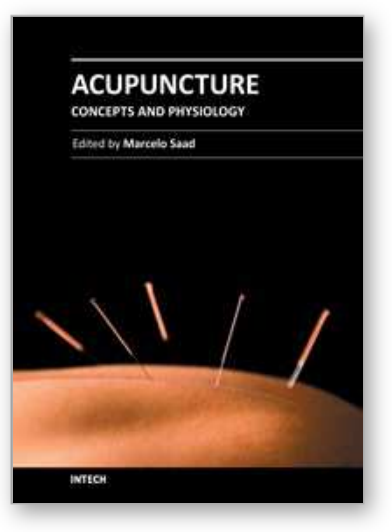

\author{
Acupuncture - Concepts and Physiology \\ Edited by Prof. Marcelo Saad
}

ISBN 978-953-307-410-8

Hard cover, 222 pages

Publisher InTech

Published online 10, October, 2011

Published in print edition October, 2011

Acupuncture and related techniques are useful tools for treating a spectrum of diseases. However, there are still many areas of controversy surrounding it. We hope this book can contribute to guide the advance of this ancient medical art. In the present work, the reader will find texts written by authors from different parts of the world. The chapters cover strategic areas to collaborate with the consolidation of the knowledge in acupuncture. The book doesnâ€ TMt intend to solve all the questions regarding this issue but the main objective is to share elements to make acupuncture more and better understood at health systems worldwide.

\title{
How to reference
}

In order to correctly reference this scholarly work, feel free to copy and paste the following:

Sheng-Hsiung Hsiao (2011). A Neurovascular Blood-Flow Modulation Model via Acupuncture Induced Nitric Oxide, Acupuncture - Concepts and Physiology, Prof. Marcelo Saad (Ed.), ISBN: 978-953-307-410-8, InTech, Available from: http://www.intechopen.com/books/acupuncture-concepts-and-physiology/a-neurovascularblood-flow-modulation-model-via-acupuncture-induced-nitric-oxide

\section{INTECH}

open science | open minds

\section{InTech Europe}

University Campus STeP Ri

Slavka Krautzeka 83/A

51000 Rijeka, Croatia

Phone: +385 (51) 770447

Fax: +385 (51) 686166

www.intechopen.com

\section{InTech China}

Unit 405, Office Block, Hotel Equatorial Shanghai

No.65, Yan An Road (West), Shanghai, 200040, China

中国上海市延安西路 65 号上海国际贵都大饭店办公楼 405 单元

Phone: +86-21-62489820

Fax: +86-21-62489821 
(C) 2011 The Author(s). Licensee IntechOpen. This is an open access article distributed under the terms of the Creative Commons Attribution 3.0 License, which permits unrestricted use, distribution, and reproduction in any medium, provided the original work is properly cited. 